\section{Towards Sustainable Local Governance in Afghanistan}

\section{Yoshiko Ogawa}

Former Livelihood Development Advisor to UN-Habitat in Afghanistan, Hanoi 10ooo, Vietnam

Received: January 24, 2014/ Accepted: February 3, 2014

\begin{abstract}
There is no doubt about the importance of local governance institutions for building sustainable peace grounded in local conditions and specificity. Such efforts have been taken in Afghanistan to facilitate a community level governance structure. UN-Habitat has been working in Afghanistan for decades to support community-based planning and implementation of projects on basic infrastructure and livelihoods improvement, through the People's Process, a people-centered approach to development. This article takes examples to demonstrate how engagement of communities contributes to enhanced trust among community members, and can lead to strengthening local governance structures, catalytic to local-level peace-building.
\end{abstract}

Keywords: the People's Process, Community Development Council, local governance, peace building

\begin{tabular}{l}
\hline Abbreviations: \\
\begin{tabular}{|lll|}
\hline CDC & $:$ & Community Development Council \\
NSP & $:$ & National Solidarity Program (in \\
& & Afghanistan) \\
CDD & $:$ & Community Driven Development \\
UN- & $:$ & United Nations Human Settlements \\
Habitat & Programme \\
\hline
\end{tabular}
\end{tabular}

\section{Peace building and local governance}

State-building and peace-building of a fragile country have drawn attention of international communities for the last decade as demonstrated by the increase in the number of multidimensional peace-keeping operations and statebuilding support undertaken by UN and the international community. Local governance, defined as "the systems, institution and processes through which local authorities interact with, and provide services to citizens and other forms of association" ${ }^{\text {, } 1]}$,

\section{Corresponding Author}

Tel.: +84 (0)94 337 8009.; E-mail: yoshiko.tip.vn@gmail.com which ensures downwards accountability and legitimacy of the state authority, is indispensable for durable stability and peace. Local governance is also "the mechanism by which citizens themselves meaningfully articulate their interests and needs, mediate their differences, and exercise their rights and duties" ${ }^{\text {[1] }}$, assuring democratic and inclusive decision-making with local participation. The World Development Report 2011 emphasizes that legitimate institutions can be only effective "immune system" to social stress and shocks leading to violence and instability ${ }^{[2]}$.

Thus, in order for fragile countries to transform into a stable state with sustainable peace, good governance at both the central and local levels needs to be promoted. However, nation-wide state-building as well as peace-building efforts often focus on development of central governments' capacity and national level reconciliation with predetermined agenda of foreign powers, guided by supplydriven processes ${ }^{[3]}$. Such top-down approaches to statebuilding and peace-building tend to ignore on-the-ground dynamics and local concepts of peace ${ }^{[4][5]}$. Grandiose peacebuilding and state-building projects, seeking visible results in short-term, turned out ineffective and even counterproductive ${ }^{[3][6]}$. Bottom-up, inclusive approaches have emerged as an alternative or complement to top-down approaches $^{[7]}$.

\subsection{Afghanistan after 2001}

In Afghanistan, whose recent history is characterized with historical and political power struggles between central authorities striving to bring about social change and local opposition as well as among local power-holders, rural development has been a critical issue for national political and social stability. Modernization efforts, which started in the early zoth century, were followed by prolonged conflicts under the communist regime after the Soviet invasion in1979, the struggle to liberate the country, power struggles among Mujahedeen forces, and the period of Taliban rule.

After the collapse of the Taliban in 2001, financial and technical assistance from foreign donors poured into the country. Development work has been undertaken at all levels from the national level to communities in remote and isolated districts. Despite the progress on many fronts, such as that in education and health sectors, numerous challenges remain. Weak governance mechanisms, widespread corruption and limited access to basic services are the cause of disillusionment and frustration among Afghan people. Strong ethnic and tribal divisions compound the situation and engender political instability of the national politics as well as village social relationships. In 
Afghan communities, social relationships consist of a network of relationships of marriage, social and financial transactions within a complex ethnic and tribal composition. Patron-client relationships are prevalent, securing survival of the vulnerable, at the same time maintaining unequal relationships and social hierarchy ${ }^{[8]}$. A weakened social fabric, insecurity and economic hardship, all have affected the pace of development work at the community level. The division between urban elites and ordinary Afghans, especially rural population, and entrenched mistrust of the central government prevails, which makes inclusive social development a critical component of social stabilization in Afghanistan ${ }^{[9][10]}$.

\subsection{Community-driven development program in Afghanistan, National Solidarity Program}

In response to the need for bottom-up peace building, the National Solidarity Program (NSP), a flagship national program of Afghanistan was designed. It is a communitycentered, Community Driven Development (CDD) program. It started in 2003 by the Ministry of Rural Rehabilitation and Development (MRRD) of the government of Afghanistan, funded by the World Bank and a multi-donor trust fund. As well-known success case with high return for investment ${ }^{[1]}$, NSP have been the subject of a number of reports and papers. This section presents the impacts and challenges of NSP on the local governance discussed in the literature in order to highlight the importance of flexibility in program implementation and understanding of the contexts in order to achieve positive governance outcomes.

Given the legitimacy of the transitional government in the eyes of the rural population was at high stake, NSP aims to enhance community-level governance by strengthening communities' capacity for project management, and, at the same time, improve community infrastructure for better access to social services. The program also aims to make the government visible and accountable to the rural population. Communities are mobilized to form a local decision-making institution, Community Development Council (CDC), elected by community members by secret ballot. CDCs, in consultation with community members, draw a Community Development Plan, prioritize development projects, submit proposals to MRRD for funding, and implement the project on their own. A community with minimum 25 families receives funds of USD 200 per family. For NSP implementation, MRRD contracts with Facilitating Partners (FPs) composed of international and local NGOs and one UN agency. FPs support the community in the election, planning, implementation and monitoring of community projects. As of 2011, NSP has mobilized 31,642 communities [12] out of estimated total number of more than 42,000 villages ${ }^{[3]}$ across Afghanistan. NSP has laid "a foundation for local governance" ${ }^{\text {[14] }}$.
In its implementation a number of challenges have faced NSP. Among others, the two most contentious issues in the process of NSP facilitation are CDC's roles in relation to the local power structure and women's participation in local decision-making process ${ }^{[0][15]}$. CDCs are established primarily to manage the community projects; however, it also aims to enhance community solidarity and capacity through democratic election of representatives, who should represent voices of community members including the vulnerable and powerless. As widely known, shura (or jirga, a traditional council of elders in communities) has played a community decision-making role in the Afghan society for long, though its functions and power vary from community to community due to socio-cultural variance and social and demographic changes. Some communities are dominated by local power-holders, who may be from wealthy families, warlords, or respected lineages ${ }^{[5]}$. Establishment of CDCs could be threatening to these existing power-holders. There are cases of power struggles between community elites when they cannot agree on the use of project resources, or a traditional shura feels marginalized by changes in local governance mechanisms, which can undermine implementation of the program as well as community stability ${ }^{[9][16]}$. At times, CDCs' legitimacy as a local decisionmaking institution is questioned and CDCs are blamed for corruption and renewed instability ${ }^{[17]}$.

Another area of opposition is women's participation. Traditional local institutions have excluded women from decision making ${ }^{[9]}$. Women's participation in the NSP process has been problematic in Afghanistan, where cultural barriers restrict women's mobility and participation in public affairs. Like elsewhere, 'gender' tends to be understood as women's empowerment and runs the risk to be regarded as a foreign imposed concept ${ }^{[18]}$ and so does NSP's attempts for inclusion of women ${ }^{[19]}$.

In dealing with customary local institutions and powerholders, FPs employ various methodologies according to the local conditions and own principles and available resources. As a result $C D C$ s take varying composition and functions according to their social environment ${ }^{[9][19]}$. How the local institution building evolves also depends on quality and intentions of the local leaders. In some cases, existing power-holders were integrated into a $\mathrm{CDC}^{[20]}$. In other cases, a traditional shura and a CDC fulfill separate functions; while a CDC is responsible for development activities, shura takes responsibility for decision-making on other community matters. Yet, there are CDCs which expand their role to include wider community decision-making as a local institution representing the whole community and resolve community conflicts ${ }^{[10][15]}$. Instances are reported, in which CDCs resolve tribal, clan and familial tensions where other local authorities prove ineffective ${ }^{[16][19]}$. CDCs could complement "the traditional shuras' local governance in general, while introducing values such as transparency, accountability and representative leadership" ${ }^{[16]}$. 
As for gender, since CDC establishment and inclusion of women in the development process are a required step before submission of a project proposal for NSP funding, FPs have to find ways to get community's consensus to set up a CDC with women's involvement. They negotiated and employed flexibility according to the local context of each community, which resulted in a variety of forms of CDCs such as mixed CDCs and women-only CDCs. Even when mixed CDCs are formed, some have meetings with men and women sitting together, and others have separate discussions. In this way NSP managed to create "a forum for discussion" for women on their priority issues such as health, domestic violence and literacy that "women could not discuss before" [16]. Introduction of a new local governance system can lead to tension in communities at the beginning; however, in the long-run, they may lead to a stronger basis for peace by empowering community groups and building local institutions. Balancing and handling these positive and negative impacts is important in the post-conflict context ${ }^{[21][22]}$.

Positive outcomes of the program for local governance and peace-building include perception of increased community solidarity, improved visibility of the government and the faith in the government system, and enhanced capacity of communities through "establishment of legitimate form of local governance" ${ }^{[16]}$. An inclusive and democratic way of local processes are especially important for building and enhancing good governance when the national government is weak and its service delivery is insufficient. It helps to find indigenous solutions for the lack of services to benefit people equally; at the same time it helps communities to claim their rights and make the national government accountable for its own actions. It is widely claimed that in Afghanistan school buildings built by the NSP are less likely to be targeted and destructed by Taliban compared to those built by other aid projects ${ }^{[23]}$ or those in communities without NSP presence ${ }^{[24]}$. This demonstrates that when taking responsibility, the communities strive to protect their own work, their facilities and infrastructure for common goods. A randomized impact evaluation also presents positive effects on subjective economic wellbeing and attitudes to the central and local government ${ }^{[25]}$. Amelioration of ethnic inter-community tension is also reported ${ }^{[19]}$. Different ethnic groups cooperated for joint projects, which facilitated intercommunity communication and cooperation. There are also examples of multi-ethnic CDCs. Other conflict resolution cases range from those between families to between armed groups. There is evidence of enhanced solidarity between villages where joint projects had pulled people together based on tangible benefits ${ }^{[16]}$.

Facilitation of such processes requires in-depth knowledge about the social relations and practices within the particular community on the FP side ${ }^{[3][18][26]}$. Precedent studies have noted that critical roles FPs play in mobilization of communities, capacity development of CDCs and facilitation of these processes ${ }^{[16][19][22]}$. FPs mobilizes, train and provide technical support to the communities. Facilitation and technical skills among FP staff is one of the determining factors for successful election, facilitation and training ${ }^{[16]}$. International Rescue Committee, one of the FPs, ensured to hire social organizers locally ${ }^{[20]}$.The relation of the communities with FPs affects communities' perception towards a CDC as well ${ }^{[9]}$. Facilitation is not only technical but also relational; all FPs interviewed in an evaluation study said that it was not possible to obtain communities' genuine participation without trust of the community in FPs, which is never easy to win ${ }^{[16]}$.

Despite reported positive outcomes, it is also urged to take positive economic, social and governance outcomes with caution. Rigorous reviews of CDD programs' outcomes found mixed results ${ }^{[22][27]}$. Mallett and Slater states that although "many of the impacts of social funds [of the World Bank] and CDD programs in conflict-affected situations are encouragingly positive", "the evidence in this area is much more mixed and far less convincing" ${ }^{\text {[27] }}$. However, it should not be concluded hastily that these methodologies do not work as expected. As seen above, implementation of the Program on the ground requires varying forms of adaptation and subtle facilitation. When aggregated for program evaluation, differences in context and outcomes among cases may not be reflected in the results. In fact, Mallett and Slater also draw attention to "the importance of programmatic and contextual dynamics" ${ }^{[27]}$. The following section presents how a people-centered approach can be employed to support the community development process by facilitation reflecting contexts in program implementation.

\subsection{People's Process, a people-centered approach to development}

The People's Process is a people-centered approach to development which UN-Habitat ${ }^{[28]}$ has promoted since 1984for slum upgrading programs, for post-disaster and post-conflict recovery and reconstruction in Sri Lanka, Pakistan, Indonesia, and Afghanistan, and further developed through involvement of UN-Habitat in recovery and reconstruction efforts in the region. It is a principle of development that places the disaster/conflict affected population at the center of the recovery process. The People's Process is based on the belief in the potential of the affected people, their ingenuity, creativity, and resilience especially when the government is weak, absent or equally affected by a natural disaster or conflict.

The People's Process consists of the following elements ${ }^{[29]}$ : community mobilization, community action planning, community contract and implementation, and monitoring. 
Community mobilization is the very first step for the communities to take charge of their own recovery and development. Although community mobilization may require extended period of time for communities to be able to assume responsibility for a development initiative, experience shows that the process of enhancing community solidarity eventually results in a faster and sustainable recovery and development with informed decision-making by the communities. At a large meeting community members form small groups of 10 to 15 families. Two members from each group form a Community Development Council (CDC), and elect representatives of the community by direct secret ballot or consensus. Gender consideration is taken into account, requiring that either the chairperson or the deputy should be a woman though this requirement needs adaptation in Afghanistan. Constitutions or by-laws to clarify responsibilities and duties of each CDC member and the community are established and agreed upon by all community members. This process makes the CDC accountable to the community.

Community Action Planning is a process for the community organization to discuss, identify, negotiate and prioritize the needs to be addressed, and prepare a plan considering all options within the available budget. After exploring possible solutions and available resources, a detailed implementation and monitoring plan is developed. All the process was facilitated and supported by social organizers of the project/program who work closely with the community members, from community mobilization to implementation and evaluation of community projects. The role of social organizers is critical in this process. They have to clearly articulate the trade-offs of the different options without imposing own opinions. Finally the Community Action Plan has to be presented to the entire community for their inputs and consensus.

Once the projects are approved, communities as a registered entity enter into a contract with UN-Habitat for project implementation. Physical work is carried out by community members unless technical requirements are beyond their capacity. Community implementation is to place accountability and monitoring in the hands of the community members who will benefit from the project. The experience of project management stays within the community and helps the community carry out more community development projects, gathering internal and external resources. This also provides them with income and skills development opportunities.

Awarded funds are disbursed according to the progress of the work. Throughout the process the project staff members work together with the community, facilitating meetings and providing advice. This is a development methodology which puts emphasis on community members to act on their own development needs through careful planning and implementation of community projects. It builds trust and accountability, and creates the preconditions for a local governance system of their own to evolve. The People's Process is an approach which can enhance communities' sense of ownership and trust among themselves.

In fact, the above process is quite similar to the process of NSP and other CDD programs. The similarity of the methodology of the People's Process to that of NSP and UNHabitat's long engagement in community development in Afghanistan qualify UN-Habitat taking a leading role among FPs; UN-Habitat contributed to development of the program design ${ }^{[30][20]}$ as well as training manual of NSP.Nonetheless, difference lies in that the People's Process as an approach can actually include a wider spectrum of implementation from this formalized process at the one end and a looser form of implementation on the other. The essence is that the approach is to support people improving their lives by planning their own settlements ${ }^{[31]}$. The Community for a Program in Mazar-e-Sharif, a provincial capital of Balkh province, developed by UN-Habitat in 1995, is an instance of a process without formalized procedure. Community For a, with support of social organizers of UNHabitat on the ground, addressed needs identified by community members, taking action for the sake of common goods. The program, which started as a construction project at the beginning, took a process-oriented approach with extensive consultation with community leaders and government officials ${ }^{[30]}$. The consultation gradually evolved into action plans according to the needs emerging in the process. The planned activities ranged from literacy projects to income generation initiatives. In particular, women social organizers assisted widows, who were in extreme difficulty, being inhibited from going outside of their homes unaccompanied. Many lacked a regular source of income. The project protected these women from becoming completely destitute, and helped them to earn small amounts of money from bread baking and other activities. This initiative was replicated in Kabul, Herat, Farah and Kandahar provinces and two rural areas in Bamiyan and Panjshir provinces by mid-1999.The work of women social organizers required subtle and delicate diplomacy with Taliban officials and mullahs at both the government and local levels. Carrying out community development work under the Taliban regime necessitated a discreet and lowkey manner, relying on its network of supporters at the community level ${ }^{[32]}$. This shows that the social organizers had thorough knowledge of the local context, and that the social organizers enjoyed the trust of the community members and even local Taliban officials towards them, which nurtured by its process-oriented and people-centered approach.

The approach, thus, strives to nurture social capital within communities, internal ties, or bonding social capital, and that of bridging nature ${ }^{[33]}$. Both types of social capital bring together and create links between different levels of 
social groups such as families, tribes and communities. In Afghanistan traditionally the bonding force within extended families and tribes is especially strong, providing mutual support, whereas bridging forces create and change alliances between them. Villagers develop, maintain and utilize social relations among community members for social and economic survival ${ }^{[4]}$. Therefore a communitycentered People's Process is not a totally new and alien concept ${ }^{[35] .}$ It tries to strengthen and channel the social capital of communities into development work.

\section{Case studies}

This section presents two cases, purposive samples, from urban and rural areas of Afghanistan where community mobilization process was facilitated following the steps of the People's Process described above, to look into the community level dynamism during the facilitation. The cases were originally reported to the UN-Habitat Kabul country office by field mangers in 2011 (Adalat case) and by an international staff after his field mission in 2012 (Baborian case) in the efforts to collect success cases in community-centered development across the projects implemented by UN-Habitat. In order to understand the process and supporting factors, separate sets of questions were sent to national managers in charge of the projects to obtain detail information on the contexts such as location, brief history and social relations of the communities, facilitation process, women's participation, and the accomplishment of the projects. Information requests were relayed to the social organizers who actually facilitated the communities in the cases. The data was analyzed in order to identify the factors conducive to the success of the cases. In the course of data analysis, the importance of facilitation became clear and the profiles of the organizers in charge were collected. Further information for clarification and elaboration on the cases, and views on community development and quality of social organizers was solicited through e-mails from UN-Habitat senior staff in Kabul and provinces.

\subsection{Baborian Community Development Council (CDC)}

Baborian is located in the northeast part of Jalalabad city, the provincial capital of Nangarhar. Baborian is a flat area with 260 houses. Much of the population fled the area during the period of the Taliban rule and took refuge in Pakistan. Now the area has a high number of returnees and Internally Displaced Persons (IDPs). The infrastructure was badly damaged during the war. The population, especially woman headed households, children and the differently- abled suffer problems including the lack of drinking water, the lack of secure land tenure, poor access to social services, and the lack of durable shelter. This area was considered to be an informal settlement by the municipality of Jalalabad local government. Houses were constructed haphazardly. Women had low literacy and no employable skills and there were no training opportunities.

Baborian was selected to participate in the project 'Reintegration of Returnees, IDPs through Policy, Planning and Targeted Assistance', funded by the European Union. The major aims of the project were twofold. The first was to enable vulnerable households, including returnees and IDPs, to address their immediate and pressing needs for shelter and basic services while establishing and strengthening local governance institutions to support their integration into the wider governance structure. The second was to create opportunities and remove obstacles which impeded people's investment in housing and related services. Community mobilization started in March 2010. Social organizers went to see the community and religious leaders to explain the project and its activities. In order to set up a female $C D C$, the social organizers went to the male community leaders and explained how the project would involve community women. It was not possible to form a female CDC without agreement of the whole community.

Even after male and female CDCs were established the activities did not go well. Unlike rural communities, in general urban community members are not related each other and rarely have large community meetings. Most of them lived in a rented house and were not interested in investing for community infrastructure development. Both men and women were not keen to attend meetings. Men were busy to earn an income to support their families. Women were also busy at home. A previous experience with some NGOs that came to the community, took pictures of women and left without bringing any projects, had made them suspicious. The social organizers kept trying to convince the community members and their persistence gradually changed such attitudes. After almost a year, the social organizers became sure that trust of the community had developed. Problems were discussed and further analyzed, and then prioritized with the participation of the whole community through small and large meetings. Throughout this process the social organizers and engineers of the project provided technical support. They assisted with planning, proposal writing, and management of community projects, and improved the local capacity to continue development work. They did not limit their work to the project activities. They acted as close friends and mediators to resolve conflicts in the community. When there was an incident of wife beating, a female social 
organizer went to see the wife, the CDC, and the husband. She asked the husband the reason for the beating, and used all the resources and skills at her disposal in an effort to convince him not to beat his wife again. The social organizers also presented themselves as role models for the community, showing how the social organizers, who are just like anyone else in the community, can work with an international organization.

A female CDC member was happy with the change in the community and drew a picture of a dove (a symbol of peace) bringing a beautiful flower to the community on an organogram of the CDC to put up in the CDC office, about five months after the start of the community mobilization process. She was happy with the establishment of the CDC and community work, and wanted to encourage the CDC and the community members to keep working together to make their lives better, bringing their resources together. This drawing by a woman CDC member is an expression of hope and aspiration for peace, presented to the community in order to urge its members to protect and nurture the sense of peace and solidarity in the community, where social capital was weakened after hardship of the civil wars and survival, and as a result of population movement.

After completion of the community projects, a social audit was carried out, reporting all expenditures, activities and results of the implemented work to the public. The major achievements of the community development projects reported by the social organizers include, (i) improved community infrastructure; (ii) capacity building of CDC as well as five women community members; (iii) registered $C D C$ status with the municipality as a legal entity; (iv) linkage of the $\mathrm{CDC}$ with other government departments and NGOs;(v) enhanced ownership of the assisted project and trust and confidence among the CDC and community members; and (vi) strengthened sense of responsibility as active players in socio-economic activities.

The community, now linked to the municipality as a registered entity, and with an enhanced capacity to plan and manage its own projects, can access additional support from other aid agencies and the government more easily than before. The social organizers observe that the community has a better idea about how institutions such as the government and media work, with a window open to the outside world.

\subsection{Adalat Cluster Community Development Council (CCDC)}

Adalat Cluster CDC (CCDC) was formed in the Nahre Shahi District of Balkh province in the Northern Afghanistan. UNHabitat started working in the area in 2003 under the
National Solidarity Program as an FP, and facilitated the formation of $\mathrm{CDCs}$ in individual communities. However, it came to evident that individual communities cannot construct certain rural infrastructure such as roads connecting multiple communities. Such common needs of multiple communities require joint design, planning and budget management; therefore, CDCs with common needs were clustered to undertake larger scale community projects.

In Adalat $\mathrm{CCDC}$, there are five $\mathrm{CDCs}$ with varying size and ethnic composition. Three of them have mainly Hazara population whereas the remaining two have Pashtun and Tajik communities. The residents of this CCDC are mostly poor farmers and returnees. For many years they have been suffering isolation and the lack of basic social services. Lack of a good road network hindered any attempts towards development.

Facilitation of the CCDC began in March 2010 and CCDC project implementation commenced in October 2010. The first step was Community Action Planning in which all the communities had to agree on the work plan and responsibilities of each community. However, from the beginning, one of the five CDCs, Gormer CDC did not show any interest in the planning and did not attend the meetings. Gormar CDC had a historical rivalry with Qizilabad CDC, another community belonging to the Adalat CCDC. This ethnic tension came to a peak during the Taliban regime when around 8o Pashtun and Hazara people in the area were killed. Since then distrust and enmity between these two communities had dominated the people. No one from Gormer and Qizilabad travelled to the other. The project in Adalat CCDC came to halt.

As a third party to the communities, the social organizers talked with a various parties of the communities as well as elders to prove that they took no one's side and bring out the issues common to all and gain trust of the community members. After a series of meetings and consultations among the CCDC member communities, Gormar CDC finally agreed to participate in the community planning meeting. The meeting elected CCDC committee members in a transparent way. They agreed to prioritize community development projects of Adalat CCDC. The four projects included grid extensions, construction of four water reservoirs, and cluster community road improvement.

The completion of the road project made the area more accessible and safer for driving. About 3,00o person-dayworth jobs for community members were created during the project. Qizilabad and Gormar communities had a ceremony to officialize their renewed relationships, and now visit each other for social functions such as weddings and funerals. The residents of the rival villages have 
managed to put behind their 13-yearconflict in the process of joint project management. The project offered an opportunity to enhance trust among the communities.

\subsection{Development project and local governance}

The two cases above demonstrated improvement of community solidarity in the course of community development projects. The first case, Baborian shows facilitation of formation and operation of the CDC and the successful joint undertaking of community projects by the community and the municipality. These helped nurture intra-community trust and confidence. The social organizers facilitated the process with patience. They presented themselves as a role model belonging to the community, to encourage them to have confidence and trust. In general at least 10 visits to the communities are necessary to get sufficient trust to start facilitation process $^{\left[{ }^{36]}\right.}$. It took one year for social organizers to notice attitudinal positive changes in the Baborian community.

The case from the Gormer and Qizilabad CDCs showed the People's Process's contribution to inter-community peace-building. The longstanding sharp division and deepseated resentment seemed impossible to reconcile at the beginning. Persistent negotiation and persuasion by neighboring communities and the project staff made apparent the benefits of cooperation to the Adalat CCDC communities, especially the two communities in conflict. Once they began interacting and working together the relationship between the two communities dramatically improved. This gave confidence to the neighboring communities as well. Although the future course is unknown, it can be safely said that the formation of Adalat CCDC has created a sense of a larger 'community', pushing the boundary of the communities.

The two cases above showed that the People's Process can provide an opportunity and methodology to initiate interaction, deepen mutual understanding, and consolidate social capital of community members. Seemingly, the Baborian case presents enhanced 'bonding' social capital and the Adalat case 'bridging' social capital. Community development work using the People's Process established clear and agreed upon procedures. Transparency of decision-making processes and resulting trust in the system are vital ingredients for good governance. Experiences of successful management of community projects under the guidance of project staff brought confidence and trust of the community members to the CDCs.

Regrettably, the above cases did not demonstrate a positive influence of the process on gender relations. Women participated in discussions and decision-making for the community projects as CDC or community members. When it comes to physical work and monitoring of construction, as well as peace-making negotiation, their participation was limited or non-existent. Though the Baborian CDC provided income generation training for women, management and monitoring of infrastructure projects were limited to men and had little to offer to women to develop their capacity. Project implementation and the episode of reconciliation in Adalat CCDC did not mention any roles of women. This means that either no woman was involved at all, or that contribution by women was not recognized even if women exerted any influence on male family members behind the scene. Certainly community mobilization has an indispensable role as the first step to capacity development of women community members ${ }^{[37]}$, but more needs to be done to involve women in community development. Training and mentoring for project management including procurement and financial management, and support to build enabling environment to participate in activities outside of home are vital to promote women's participation ${ }^{[14][19]}$. Active presence of women social organizers with careful facilitation and negotiation skills and thorough knowledge about the local conditions is the key to capacity building of women ${ }^{[9][15][16]}$.

What stood out in the cases above and the literature on NSP is the complexity of and subtlety required in the facilitation processes. These projects and programs are not only about community infrastructure development but also about a social change. This makes facilitation of the process by competent and knowledgeable facilitators, in this case, social organizers, indispensable ${ }^{[4]}$. Social organizers' familiarity to the area as well as their qualification and experience in facilitation are central to win the trust of communities, which is the essential prerequisite for effective facilitation ${ }^{[1]}$. The social organizers in the above cases tried to position themselves as a trustworthy close friend, in the Baborian case, and a neutral, third party to the conflict, in the Adalat case. These requirements pose difficulty in securing an enough number of competent social organizers. This clearly shows a need for continuing training of new and old staff so that the program can retain sufficient number of capable staff on the ground ${ }^{[16]}$. Cascading training can spread the knowledge at reasonable costs but it is not always the best option especially when the skills to be trained are practical skills ${ }^{[38]}$, adapted according to fluid contexts. Daily mentoring and on-the-job training are found to be useful in the field. Social organizers share their daily achievements and challenges with other staff to cultivate their knowledge and skills. Such accumulated tacit knowledge is an invaluable asset to the organization. It is a challenge to critically analyze such daily learning and 
systematize and institutionalize into training curriculum of the program ${ }^{[10][22]}$.

\section{Conclusion}

This young local governance structure had support of the project staff, and was connected to the local government as a legal entity. Desire of community members to be recognized as a formal institution urged to promote accountability and sustainability of the new structure. Engagement of citizens with the local government through CDCs and CCDCs are not only the basis to allow communities to build community infrastructure, but also to provide a channel to claim for public services and good governance on the side of the government. The importance of placing ordinary Afghans at the center of local governance, with more attention to women's empowerment, cannot be overemphasized.

Improving the quality of governance in Afghanistan's cities and rural areas and increasing the capacity and accountability of local governments is critical for political stability and development. Of necessity is long-term support to the community level governance, ensuring transparency and accountability within communities, and the building of the local governments' capacity to recognize and collaborate with such local governance mechanisms ${ }^{[39]}$. The People's Process has proven to be an approach in which good governance can be facilitated as well as a vehicle for cost effective delivery of essential services and infrastructure. It worked because of the flexible adaptation, in-depth knowledge of facilitators on the contexts, and persistent trust building. At the national level, a large scale programs are needed to extend the impacts. Programs should be designed to allow rooms for adaptation on the ground and learning from experiences while establishing a mechanism of monitoring to support the field level implementation and ensure quality facilitation of community activity processes.

\section{Acknowledgements}

The author would like to express her gratitude to the colleagues of UN-Habitat in Afghanistan, Jan Turkstra, Wataru Kawasaki, Peter Dalglish, and the national project managers and field staff, Nagib Amiri, Nasrullah Habibi, Niamat Rahimi, Salem Helali, Haji Maroof, Benazer,Qader Shakiri, and Ahmad Farid Omary, and a regional officer, Lalith Lankatilleke, for providing information, inputs and comments to an earlier version of this paper.

\section{References and notes}

[1] UNDP. Governance for Peace. NY: UNDP; 2012.

[2] World Bank. World Development Report 2011: Conflict, Security, and Development; Washington DC: World Bank; 2011.

[3] Suhrke A. When More is Less: The International project in Afghanistan. New York: Columbia University Press; 2011.

[4] Campbell S. Constructing Top-down as Bottom-up: The Governmental Co-option of Peacebuilding "From Below".vis-àvis: Explorations in Anthropology. Vol. 11, No. 1; 2011.p.39-56.

[5] ChopraJ,Hohe T. Participatory Intervention.Global Governance 10.p.289-305; 2004.

[6] Stephenson J, McCall R, and Simoians A. Not in Our Image: The Challenges of Effective Peace-building. Prism Vol. 1, No. 2. 2012. p.123-132.

[7] Waldman M. Community Peacebuilding in Afghanistan: A Case for a National Strategy. London: Oxfam International; 2008.

[8] Kantor P, Pain A. Securing Life and Livelihood in Rural Afghanistan - The Role of Social Relationships. Kabul: AREU; 2010.

[9] Boesen IW. From Subjects to Citizens: Local Participation in the National Solidarity Programme.Kaul: AREU; 2004.

[10] Zakhilwal O, Thomas JM. Afghanistan: What Kind of Peace? The Role of Rural Development in Peace-Building, Working paper, November 2005, "What Kind of Peace is Possible?" project; 2005.

[11] Zoellick R. The Key to Rebuilding Afghanistan.Washington Post (22 August 2008)

[12] NSP/MRRD. Monthly Program Report (20 February to 19 March 2012).http://www.nspafghanistan.org/files/201203\%2oProgram me\%2oMonthly\%2oReport\%2oMarch\%202012\%20_29th\%2oHo ot\%201390_.pdf; 2012.

[13] NSP/MRRD.NSPdefinitions.http://www.nspafghanistan.org/def ault.aspx?sel=15; 2012.

[14] E-mail communication with UN-Habitat national staff, 4 February 2013.

[15] Kakar, P. Fine-Tuning the NSP: Discussions of Problems and Solutions with Facilitating Partners.Kabul: AREU; 2005.

[16] Barakat S. Mid-term Evaluation Report of the National Solidarity Programme (NSP), Afghanistan, May 2006, York: Post-war Reconstruction \& Development Unit, The University of York and Ministry of Rural Rehabilitation and Development, Islamic Republic of Afghanistan; 2006.

[17] Brick J. The Political Economy of Customary Village Organizations in Rural Afghanistan, paper prepared for the Annual Meeting of the Central Eurasian Studies Society. Washington, DC; September 2008.

[18] Abirafeh L. Lessons from Gender Focused International Aid in Post-Conflict Afghanistan Learned?, Friedrich-Ebert-Stiftung. http://library.fes.de/pdf-files/iez/o2978.pdf; 2005.

[19] ACTED. Transition Strategy and Cycle 2+ Communities: A Study of NSP, March-May 2007.

[20]Maynard K. The Role of Culture, Islam and Tradition in Community DrivenReconstruction: A Study on the IRC's Approach to Afghanistan's National SolidarityProgramme. The International Rescue Committee; 2007.

[21] King E.A Critical Review of Community-driven Development Programmes in Conflict-affected Contexts. London: DFID/International Rescue Committee; 2013.

[22] Mansuri G, Rao V. Localizing Development: Does Participation Work? Washington DC: World Bank; 2013.

[23] Washington Monthly. The Schools The Taliban Won't Torch. December 2007. 
[24]CARE.Knowledge on Fire: Attacks on Education in Afghanistan Risks and Measures for Successful Mitigation. http://www.care.org/newsroom/articles/2009/11/Knowledge_on _Fire_Report.pdf; 2009.

[25] Beath A, Christia F, Enikolopov R. Winning Hearts and Minds through Development Aid: Evidence from a Field Experiment in Afghanistan. Centre for Economic and Financial Research at New Economic School; October 2011.

[26]Torabi Y. Assessing the NSP: The Role of Accountability in Reconstruction. Kabul: Integrity Watch Afghanistan; 2007.

[27] Mallett R and Slater R. Funds for Peace? Examining the Transformative Potential of Social Funds.Stability: International Journal of Security \& Development, 2 (3): 49; 2013, p. 1-14

[28] The United Nations Human Settlements Programme, UNHabitat is a United Nations agency to promote socially and environmentallysustainable towns and cities with the goal of providing adequate shelter for all. In addition to its normative work on human settlements, UN-Habitat runs technical cooperation programs and projects in about 70 countries. In Afghanistan UN-Habitat has been working continuously since 1992.

[29]UN-Habitat.People's Process in Post-disaster and Post-conflict Recovery and Reconstruction. Bangkok: Regional Office Asia and the Pacific, UN-Habitat; 2007.

[30]Lister S. The Community Fora Process in Mazar-e-Sharif, Afghanistan: A Case Study.Making Aid Work in Fragile States.Washington: World Bank; December 2004.

[31] e-mail communication with UN-Habitat international officer, 17July 2013.

[32] Lemmon GT. The Dressmaker of KhairKhana: Five Sisters, One Remarkable Family, and the Women Who Risked Everything to Keep Them Safe, NY: HarperCollins; 2011.

[33] Adler PS, Kwon SX. Social Capital: Prospects for a New Concept.The Academy of Management Review.Vol. 27, No. 1; 2002. p. 17-40.

[34].Kantor P. From Access to Impact: Microcredit and Rural Livelihoods in Afghanistan. Kabul: AREU; 2009.

[35] Turkstra J,Popal AB. Peace Building in Afghanistan through Settlement Regularization, revised version of a paper presented at the $46^{\text {th }}$ ISOCARP Congress 2010.Nairobi; 2011.

[36] e-mail communication with former UN-Habitat national project manager, 13 March 2013.

[37] Echavez C. Does Women's Participation in the National Solidarity Programme Make a Difference in their Lives? A Case Study in Parwan Province.Kaul: AREU; 2010.

[38] Lowe G, Evaluation of UN-Habitat, Facilitating Partner of National Solidarity Program (internal report). July 2004.

[39] Nagl JA, ExumAM, Humayun AA. A Pathway to Success in Afghanistan: The National Solidarity Program, Policy Brief, Center for New American Security; March 2009. 